\title{
Retos de la Comisión Nacional de Reumatología
}

\author{
Ana I. Sánchez Atrio
}

\begin{abstract}
Presidente de la Comisión Nacional Española de Reumatología.

Jefe de Sección de Enfermedades Sistémicas Autoinmunes. Hospital Universitario "Príncipe de Asturias" de Alcalá de Henares.
\end{abstract}

Palabras clave: Comisión Nacional de Reumatología, formación mé-

dica especializada, MIR.

\section{Correspondencia:}

Ana I. Sánchez Atrio

झ aisatrio@gmail.com

Vivimos tiempos de cambio social y económico, e indudablemente estos cambios afectan a la organización y normalización de las profesiones, incluidas las sanitarias. Si bien nuestro sistema actual de selección y formación de médicos especialistas es considerado como ejemplo de calidad, la obligatoria adaptación y homogeneización de títulos entre los distintos países de la Unión Europea, hacen necesarios reajustes en los contenidos y en los periodos de formación de nuestros futuros médicos.

Las Comisiones Nacionales de Especialidades en Ciencias de la Salud, regidas por el Consejo Nacional de Especialidades en Ciencias de la Salud, constituyen los órganos consultivos básicos para los Ministerios de Educación, Cultura y Deporte y para el Ministerio de Sanidad, Servicios Sociales e Igualdad; reuniendo a representantes de todas las especialidades en ciencias de la salud.

El Consejo Nacional de Especialidades en Ciencias de la Salud aparece especificado en la Ley 44/2003, de 21 de noviembre, de Ordenación de las Profesiones Sanitarias. En el citado precepto legal se contempla también la creación de las Comisiones
Nacionales de las Especialidades en Ciencias de la Salud. Los artículos 28 y 30 establecen la composición y las funciones de las comisiones.

Así, cada Comisión Nacional será designada (por un periodo de 4 años) por el Ministerio de Sanidad, Servicios Sociales e Igualdad, con la siguiente composición:

1. Dos Vocales designados por el Ministerio de Educación, Cultura y Deporte, uno, al menos, deberá ostentar la condición de tutor de la formación en la correspondiente especialidad.

2. Cuatro Vocales de entre los especialistas de reconocido prestigio que proponga la Comisión de Recursos Humanos del Sistema Nacional de Salud.

3. Dos Vocales en representación de las Entidades y Sociedades Científicas de ámbito estatal legalmente constituidas en el ámbito de la especialidad.

4. Dos Vocales en representación de los especialistas en formación, elegidos por éstos, en la forma que se determine reglamentariamente. 
5. Un vocal en representación de la Organización Médica Colegial. Si la especialidad puede ser cursada por distintos titulados, la designación del representante se efectuará de común acuerdo por las corporaciones correspondientes.

Las funciones encomendadas legalmente de la Comisiones Nacionales de la Especialidades en Ciencias de la Salud son las siguientes:

1. La elaboración del programa formativo de la especialidad.

2. El establecimiento de los criterios de evaluación de los especialistas en formación.

3. El establecimiento de los criterios para la evaluación en el supuesto de nueva especialización.

4. La propuesta de creación de áreas de capacitación específica.

5. El establecimiento de criterios para la evaluación de unidades docentes y formativas.

6. El informe sobre programas y criterios relativos a la formación continuada de los profesionales en áreas funcionales específicas dentro del campo de la especialidad.

7. La participación en el diseño de los planes integrales dentro del ámbito de la correspondiente especialidad.

8. Las que se señalan expresamente en esta ley o se determinen en las disposiciones reglamentarias dictadas en su desarrollo.

Con la entrada en vigor del Real Decreto 639/2014, de 25 de julio, se regula la troncalidad, la reespecialización troncal y las áreas de capacitación específica, se establecen las normas aplicables a las pruebas anuales de acceso a plazos de formación y otros aspectos del sistema de formación sanitaria especializada en Ciencias de la Salud, y se crean y modifican determinados títulos de especialistas.

El espíritu de este cambio está fundamentado en conseguir que los futuros especialistas tengan una "visión global e integral" del paciente, y para ello deberán adquirir una serie de competencias propias del tronco. Ello supone que todos aquellos médicos en formación de un determinado tronco adquirirán una formación homogénea y uniforme.

La Reumatología queda integrada en el tronco médico, junto a otras 20 espacialidades. Nuestros futuros especialistas tendrán que pasar por un periodo troncal de una duración mínima dos años, cuyos contenidos están aún por determinar. Sólo aquellos médicos en formación que superen el periodo troncal podrán acceder, mediante otro proceso de selección nacional, a un periodo formación específica también sin diseñar en el momento actual. Este segundo proceso de selección conlleva una incertidumbre añadida al médico en formación, y que podría solventarse si la decisión del primer examen determinara de forma definitiva la especialidad concreta elegida por el médico, como ocurre en el momento actual

Otro indudable problema es que el RD 639/2014 nace sin haberse establecido claramente, ni los contenidos concretos de los programas, ni el tiempo de formación de los dos periodos de formación. A lo anterior hay que añadir que deben reestructurarse las Unidades de Formación Docente actuales, constituyéndose "de novo" unas Unidades Docentes de carácter troncal.

Para el desarrollo del programa de formación del periodo troncal y sus criterios de evaluación se van a crear, en breve, unas Comisiones Delegadas de Tronco, constituidas por distintos miembros de las Comisiones Nacionales de las Especialidades que integran el tronco concreto.

No queda definida claramente cómo será la selección de los miembros de cada Comisión Delegada, ni su composición concreta. Siendo de vital importancia para cada especialidad, y en nuestro caso para la Reumatología, el poder participar en la elaboración global del programa formativo, tanto del periodo específico, como del periodo troncal. 
Para finalizar, el RD de la Troncalidad incluye otra novedad: las Áreas de Capacitación Específica o "conjunto de conocimientos, habilidades y actitudes, añadidos en profundidad a alguna especialidad médica" . Estas nuevas Áreas de Capacitación suponen la posibilidad de profundizar en conocimientos, o ampliar la práctica profesional de los especialistas, mediante la adquisición de competencias avanzadas en determinados campos de la Medicina a través de un programa formativo específico.

En el momento actual no existe posibilidad de acceder a las Áreas de Capacitación Específica desde la especialidad de Reumatología. Está previsto que se pueda solicitar la creación de una nueva Área de Capacitación a través de las Consejerías de sanidad, del Instituto Nacional del Gestión Sanitaria o de una, o varias, Comisiones Nacionales de Especialidad.

Es de vital importancia para la Reumatología y de justicia, atendiendo al enorme esfuerzo de muchos reumatólogos que llevan trabajando y profundizando en el conocimiento de distintos campos de la Reumatología, como son la Reumatología Pediátrica y las enfermedades autoinmunes sistémicas, el que la Comisión Nacional de Reumatología, en colaboración con la Sociedad Española de Reumatología, trabajen para conseguir la acreditación de otras posibles Áreas de Capacitación Específica de claro interés social.
Opina sobre este artículo:

\section{$\mathbf{f}(\mathrm{B}$ in $8+\mathbf{s} \boldsymbol{t}$}

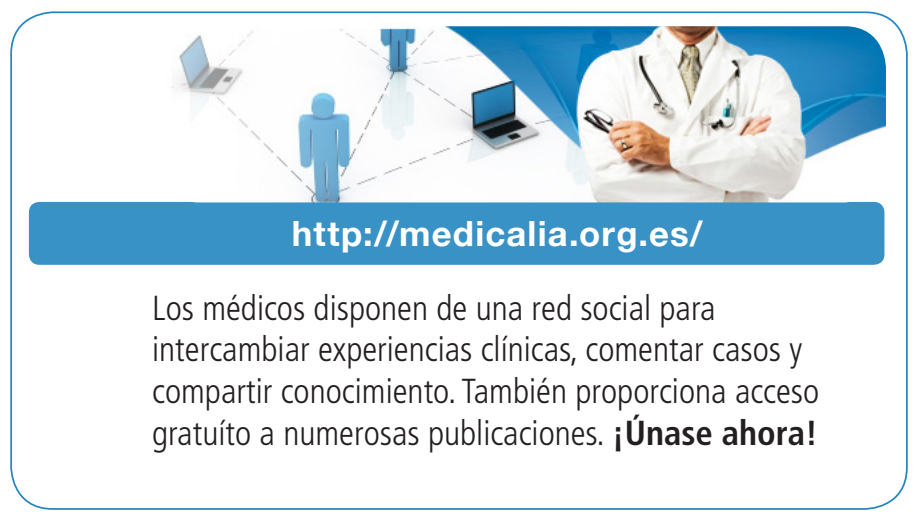

\section{Publish with iMedPub}

\section{http://www.imed.pub}

Acta Reumatológica es una revista que tiene por fin la difusión de estudios clínicos relacionados con aspectos prácticos del diagnóstico, tratamiento y seguimiento de pacientes con patología reumatológica, de estudios epidemiológicos relacionados con patología inflamatoria y musculoesquelética de presentación común o infrecuente en la práctica clínica tanto en población adulta como pediátrica, de casos clínicos de patología poco habitual o de presentaciones inhabituales de patología frecuente, de imágenes didácticas e ilustrativas en reumatología y del estado actual e innovación en la formación especializada en reumatología. 
